\title{
Utilizing Shulman's Table of Learning to Understand Learning in Professional Health Science Programs
}

\begin{abstract}
Teresa Mortier ${ }^{1}$ and Jayne Yatczak ${ }^{2}$
Abstract: Understanding student learning in health science professional programs is both timely and relevant and is the focus of this article. The Table of Learning by Lee Shulman (2002) provided a tool for an interdisciplinary reflection surrounding student learning in clinical laboratory science and occupational therapy. Utilizing the taxonomy pieces, we constructed a visual representation of how students learn in these two programs. Our work, utilizing The Table of Learning, and subsequently the design of our model allowed us as educators from two separate programs to examine the learning process. Other health care programs may view this model as a template in their interdisciplinary Scholarship of Teaching and Learning (SoTL) conversations.
\end{abstract}

Keywords: student learning, SoTL, interdisciplinary, taxonomies of learning, health science education.

\section{Introduction}

In this article we will share our insights, reflections, and subsequent understandings from our use of Shulman's (2002) Table of Learning. We used the Table of Learning to illuminate how students learn and develop in two professional programs. We thought about how students enter into practice and begin to acquire the capacities and understanding necessary to act as a member of their profession. We engaged students in a conversation through interview and focus group to elicit their perceptions, attitudes, and feelings surrounding learning. Our goal was to create a visual model of student learning in occupational therapy (OT) and clinical laboratory science (CLS) at our institution using the elements of the Table of Learning. The development of our model is grounded in the empirical data from a qualitative research study in which students described their experiences within the learning environment of each program.

\footnotetext{
${ }^{1}$ Eastern Michigan University, School of Health Sciences, Clinical Laboratory Science Program, 347 Marshall, Ypsilanti, Michigan 48197, tmortier@emich.edu

2 Eastern Michigan University, School of Health Sciences, Occupational Therapy Program, 362 Marshall, Ypsilanti, Michigan 48197.
} 
According to the Carnegie Foundation's (2008) call for studying professional education, educators must define for their programs what constitutes professional "insight, technical knowhow, and discerning moral commitment”? (Shulman, L.S. \& Fenstermacher, G.D., 2008, p.3). Throughout their time engaging in professional education, students are exposed to the cognitive, psychomotor, and affective domains of learning but how do students' experiences in the program translate to internalized professional knowledge, professional skills and commitment?

\section{Background and significance}

Our interest in student learning in professional programs is both timely and relevant as society questions the value of certain academic disciplines and focuses on programs that educate students for specific jobs. Indeed, majors that are more closely aligned with particular occupations and industries tend to experience lower unemployment rates. A study by Georgetown University (2013) reports that unemployment rates for college students who majored in health care are relatively low, 5.4\%. Conversely, this same study indicates that unemployment rates are higher in non-technical majors, such as Social Science, Humanities and Liberal Arts, and the Arts with unemployment rates of $8.9 \%, 9.4 \%$ and $11.1 \%$ respectively. The low unemployment rates of healthcare majors has led to an increase in student graduation in health care professional programs. According to the US Department of Education: The Institute of Education Sciences report (2014), "the number of degrees conferred in health professions and related programs increased by 61 percent between 2006-07 and 2011-12” (U.S. Department of Education, National Center for Education Statistics, Fast Facts, 2014 paragraph 3).

Reflecting the demand for professional education at both the state and national levels, the College of Health and Human Services, at the Midwestern state university where we teach is the second largest college in the university. The College of Health and Human Services saw the largest 
increase in student enrollment over the past several years. From 2010 to 2014 the number of graduate and undergraduate students in the college increased by 13\% (IRIM, 2014). During this same time period, other colleges at the university saw either minor increases or decreases in student enrollment. Occupational therapy (OT) and clinical laboratory science (CLS) are two of the professional programs in the College of Health and Human Services. Given the increased interest in professional programs by students and society, it is important that educators critically examine how students learn in professional programs.

The study of "professional education must have at its core a combination of ongoing personal and collective learning” (Shulman, 2002 p.39), that develops an internalized disposition in the student for further development. Eraut (2000) cautions that we cannot view knowledge as "solely individual”, but, as educators, we need to recognize that the learning context consists of a location, a set of activities, and social relations (Eraut, 2000 p. 130). We need to attend to the where, the what, and with whom which includes classroom, labs, clinical sites, content knowledge, and relationships with instructors, peers and fieldwork educators. Knowledge necessary to act as a member of a profession is supported by the norms and standards of professional organizations and societies that students become exposed to during the educational process and when they socialize with members of their chosen profession inside and outside the classroom. Bragg (1976) defined professional socialization as a process through which "the individual acquires the knowledge and skills, the values and attitudes, and the habits and modes of thought of the society to which he belongs” (Bragg, 1976 p. 9).

As faculty members teaching in occupational therapy and clinical laboratory science we are interested in better understanding how students develop an internalized disposition encouraging progress towards becoming members of their respective profession. Do they get 
there? Are we adequately preparing them to get there? What could we do better to support student learning at all points in the curriculum? This calls for studying students throughout their process of learning. Such an endeavor may help educators support the growing number of students in such programs move toward becoming competent members of their profession.

\section{Shulman's Table of Learning}

Shulman (2002) developed a taxonomy of learning, The Table of Learning, in response to the study of professional education conducted by The Carnegie Foundation for the Advancement of Teaching. An understanding of taxonomies as assessment tools led to their use as curriculum design aids, allowing educators to check their teaching for appropriate levels in all domains. Beyond their use as an aid to curriculum design the essence of a taxonomy is that it can provide educators with a "language, a set of terms for making sense" (Shulman 2002, p. 39). Prior work on taxonomies suggested that learning may have more complexity and does not necessarily occur in a "hierarchical or sequential" order (Shulman 2002, p. 40). According to Shulman, as educators, we can "make a difference" by making distinctions with the use of taxonomies (Shulman 2002, p. 38). Furthermore, he suggested that taxonomies, such as The Table of Learning, can be used in various ways which include, "a lexicon, a classification system, elements to be balanced, assessment and design framework, middle-range theory, master narrative, mnemonic, ideology and elements to be played with" (Shulman, 2002 p. 40). The Table of Learning provided us with a language through which we can share our ideas with others about professional education. Therefore, The Table of Learning offered us a coherent way of thinking about what we are doing as educators and the impact what we do has on student learning.

The Table of Learning consists of six elements: engagement and motivation, knowledge and understanding, performance and action, reflection and critique, judgment and design, and commitment and identity (Shulman, $2002 \mathrm{p}$. 38). The expected progression implied by the table 
is that learning begins with student engagement, engagement leads to knowledge and understanding, which then allows students to perform. Next, reflection on performance leads to judgment and through the process of judgment students develop commitment. Commitment leads to the internalization of values and is integral to identity. Identity and commitment to the profession brings the student back to new engagements. Shulman challenges professional programs to examine his taxonomy and its components within their educational environments. Shulman said "play with them” and that is what we did (Shulman, 2002 p. 44). In order to be effective, professional education must provide students with the purpose of the profession, content necessary to enter into practice, and access to actual practice.

\section{Methods}

Design

Our model of student learning in OT and CLS was an outcome of a larger research project. We used a qualitative approach to answer our research question:

What are students' experiences of the learning environment in a professional master's degree program in occupational therapy and a professional bachelors' degree program in clinical laboratory science and how does the learning environment contribute to their learning and development?

Human subject approval was obtained from the Institutional Review Board at our university.

The study consisted of individual interviews and focus groups. Open-ended interview guides were used for the individual interviews and for the focus groups. The open-ended questions and probes elicited descriptive responses. The guide for the individual interviews focused on students' beliefs about how knowledge is constructed, what kinds of experiences supported the feeling of being part of a profession, and what motivated them to embark on this educational program. Each interview was conducted and recorded by a member of the research team and was approximately 
45-90 minutes long. The guide for the focus groups focused on student perceptions of the programs related to program expectations, culture, and perceptions of how knowledge is constructed. Focus groups were formed with students from the first and second academic years of the OT program and a cross-section of the students in the CLS program. Each focus group session lasted approximately 1 hour and was moderated by a member of the research team. The focus group was audiotaped and the research team member took notes.

\section{Participants and Context}

Participants were recruited from first and second year occupational therapy and clinical laboratory science students. A purposeful sampling technique resulted in participants who represented various portions of the educational process in both programs. A member of the research team explained consent, confidentiality, the interview process, and the focus group process. Each participant signed a consent form. Individual interviews were conducted with seven occupational therapy students and seven CLS students. Separate focus groups were conducted to capture students' experiences of the program at the beginning and the end of their program. Focus groups were conducted with first year and second year OT students. Six occupational therapy students participated in the focus groups. The CLS focus group was conducted with three second year CLS students.

The occupational therapy program includes six semesters of coursework in which students obtain an entry-level Master's degree. Students enter the program together and progress through courses as a cohort. In addition, in the third, fourth and sixth semesters they participate in a parttime fieldwork experience in which they spend 6-8 hours/week at an off-campus clinical site. After completion of coursework in occupational therapy, students complete six months of full-time fieldwork. The clinical laboratory science program culminates with an entry-level Bachelor's degree, consisting of on-campus classroom and student laboratory experiences. At the end of the 
CLS on-campus curriculum, students are placed in a 24-week clinical rotation within a hospital setting. Fieldwork and internships are a critical aspect of both programs and are mandated by accreditation bodies. The design and structure of the OT program and the CLS program provides a framework for these experiences to occur within the context of classroom, laboratory, and fieldwork.

Data analysis

The research team consisted of a faculty member from OT, a faculty member from CLS, and three Master's level OT students. The team developed an initial framework for coding based on Shulman's Table of Learning and the literature surrounding student learning, motivation, and professional education. Interview and focus group interviews were transcribed. The transcribed data were coded, organized, and transformed into analyzable units using MAXQDA computer software. Each interview was coded separately by two members of the research team. The coding and data analysis of each researcher were compared to ensure consistency. Each code was labeled, described and defined. Our research team met every week to discuss the data, how codes were defined, and the content of key categories. The emerging initial codes were discussed, clarified, and collapsed into themes. Data collection and analysis continued until a point of saturation was achieved.

\section{Results : A tale of two programs}

The OT story

The challenge of educators in the OT program is to demonstrate to students that OT practice not only involves technical skills but professional judgment about the best course of action related to each client's condition and their social and cultural context. Furthermore, educators in the program must be able to articulate what constitutes "real" professional education in occupational therapy. All of which must be congruent with and reinforced by fieldwork experiences, which happen outside the program. 
Multiple factors lead students to pursue a degree in occupational therapy. Many enter the program as the result of having some personal experience with occupational therapy. Other sources of information and inspiration include family members or friends who are or work with occupational therapy professionals. Less often a student is directed to occupational therapy through a high school guidance counselor or academic advisor.

After identifying occupational therapy as a potential career, students begin the process of applying to the program. Application to the program requires students to complete 100 volunteer hours, the GRE, and submission of a portfolio. The desire to help people, the relative certainty of a job after graduation, the belief that occupational therapy is a good career choice for them based on their current knowledge of the profession, and taking the necessary actions required to get into the program lead students to enter the program with a certain degree of commitment. Sabari (1985) notes that the selective admission process of OT programs in general increases motivation and commitment from students.

Frequently, students enter the program with a strong commitment to the profession. As one student explained, "It's like seeing that [OT] and knowing that I'll be able to do that for somebody is just mind blowing." Students may also enter the program with a desire to work with a particular population, often times having completed their volunteer hours with that population. This initial commitment to the profession and to working with specific populations leads to engagement with content related to the population of interest. Although interest in a particular population can lead to increased engagement and acquisition of content knowledge it may also negatively affect engagement in content unrelated to that population. Because students receive a generalist education it is necessary for them to understand how to work with diverse populations and in various practice settings. 
Through engagement with new content in the classroom and new practice settings encountered during Level I fieldwork, students often develop an interest or motivation to work with populations differing from those in which they were initially interested. For example, after the older adult course and fieldwork experience students often report a new found interest in working with older adults. Conversely, students may come to realize, through their experiences during the pediatric fieldwork, that contrary to what they thought, they do not want to work with children. As a result, old commitments may diminish and new commitments may arise through a blend of didactic coursework and fieldwork. Through a combination of prior knowledge and experiences, and exposure to new content and new experiences, commitment, motivation and level of engagement waxes and wanes within courses and across the curriculum.

In addition, student engagement is influenced by their beliefs about the profession. Students enter the OT program with an array of unexamined and often erroneous assumptions about professional education and OT practice. Students in the study referred to professional education as acquiring specific knowledge, learning a trade, or a skill and expect the program to provide them with the technical skills they will need to do the job of an occupational therapist.

Many view the conceptual and theoretical knowledge of the foundational courses, which are covered in the first semesters, as unrelated to the work they will perform as therapists. Whether or not a student views content as relevant affects motivation and engagement. As one student stated, “If you don’t see it being relevant to your future, you're not going to do it.” This same student connected with certain types of knowledge stating, "I’m going to use all of these assessments that we're learning. I'm going to know these interviews. I'm going to have all these, this information to use and I see it being used when I'm in fieldwork.” 
Students clearly state a preference for classes that provide hands-on learning experiences. Frequently, these learning experiences are related to techniques that will be used in practice, such as the measurement of range of motion and strength. The professional culture of occupational therapy, which students are exposed to during fieldwork, reinforces this focus by placing a high premium on the performance of various technical skills further contributing to the failure of students to realize that hands on learning is informed by theoretical and conceptual knowledge and is not just demonstration of a technical skill.

We hope that student's participation in fieldwork leads to understanding of how to apply various types of content knowledge to practice. According to the Accreditation Council of Occupational Therapy Education (ACOTE), level I fieldwork is an opportunity for students to actively participate in aspects of the therapy process and to demonstrate understanding of knowledge acquired in the classroom. However, the theoretical and conceptual knowledge that underlies occupational therapy is often not evident during these experiences, making it difficult for students to connect theory to practice and the design of interventions. Shulman describes practice as the crucible for understanding. Practice however, often keeps hidden the thinking or judgments behind what is being done. It is essential that students be supported to reflect on and critique practice.

It is expected that through repeated practice in fieldwork that students' understanding of the domain and process of the profession is confirmed and skills related to judgment and design will be further developed and refined. Indeed, because level I fieldwork is part-time, students are often unable to fully "see" the complexities of practice. The demands of practice and the professions custom of placing students with non-occupational therapy supervisors further challenges students’ ability to understand these complexities. 


\section{The CLS Story}

Commitment to the CLS profession begins when students become aware of the profession and opportunities for employment. A survey of clinical laboratory professionals through Coordinating Council on the Clinical Laboratory Workforce (CCCLW) revealed that "75 \% of the more than 4,500 respondents were completely unaware of the profession upon graduating from high school” (Kibek, 2008, p. 2). In addition, students report that they learn of the CLS profession from family members or science advisors when they first enter higher education; and a small portion when they are searching for a career that will utilize biology and chemistry concepts. Once the students find this professional pathway that seems to meet their interests and desire and complete a program that leads to a specific job, they become committed. Following this initial commitment, students engage in classroom and on campus laboratory work to acquire the specialized content knowledge and skills necessary for their clinical rotations and eventual professional practice. Engagement throughout the program may vary as students seem to be drawn to a particular laboratory subject area. For example, after a particular didactic and student laboratory course in microbiology, immunohematology, chemistry, or hematology students become more focused on that particular area within the curriculum because of their unique tasks. The student may feel more and less engaged depending on how they view themselves performing each area's unique tasks as a member of this profession.

In all areas, however, engagement seems to be enhanced when CLS students gain access to the student laboratory on-campus. Students described that access to the student laboratory on campus allowed for clearer connection of knowledge and skills to actual laboratory practice. Shulman states that educators should spend time "worrying” about understanding (p.40). He suggests that reflection, critique and practice are crucial to develop understanding as students take "ownership” of their knowledge. CLS students described a deeper understanding of the theoretical concepts 
when they had opportunity to apply theory from the classroom immediately following in the oncampus laboratory. We believe that understanding, reflection and critique may be intertwined. For example, in our CLS on-campus laboratory, students are given a procedure that outlines the steps to complete a laboratory test. Within the procedure, explanation of the principle ties understanding of a theoretical concept to technical performance of the laboratory test. But actual performance of the laboratory test leads to overall understanding. In the on-campus laboratory, the students have an opportunity to practice within a controlled situation. As educators in CLS we hope that the design of the on-campus laboratory exercises allow for students to practice with reflection. To facilitate this we allow students to make "errors" in the student laboratory, attempting to support that they must reflect on current actions and problem-solve, albeit within a very controlled experience.

In his article, Making Differences: A Table of Learning, Shulman (2002) poses the question: "how do we lead students to judgement and design when situations that students can display understanding become "fuzzier, more variable, more ambiguous, less readily controlled”? (Shulman, 2002 p.42). I would argue that the "less controlled" situations may begin in the CLS on-campus student laboratory, but are built upon when students move to clinical rotations in the hospital. The students have more exposure to "fuzzy" situations that are essential to move them to judgment and design. The transition to utilizing judgment and design may begin in the on campus laboratory but seems to solidify towards the end of clinical rotation. One student who was almost finished with the clinical rotation said he felt he had "the information and tools" to begin his career. He found it difficult to articulate what the "tools" included. He elaborated that the "information and tools" was more than content knowledge needed to work in the lab. It included the "structure" and "styles" present in the different lab disciplines from his rotations. He felt like a part of the 
profession, with more commitment and engagement to start his career. Educators, whether in the student laboratory or clinical rotation, support opportunities to reflect during practice, but this is probably the most difficult part of the curriculum to uncover and measure.

\section{The development of our model}

Utilizing a taxonomy such as The Table of Learning provided a way to look at student learning in a different way. Examining the relationship of Shulman's pieces of the taxonomy illuminated the process of learning in OT and CLS in a way different from assessment with grades. Student grades may not adequately assess the process of becoming a professional. If we only pay attention to grades to measure student learning, we ignore the process of learning, or moving students through "the fog of learning" (Tagg 2010, p. 4). Tagg was concerned that, "students, faculty and administrators work in a state of diminished perception of those processes most relevant to learning” (Tagg 2010, p. 1). The pieces of the taxonomy are familiar to us as educators, and we were fascinated by the thought of playing with the Table of Learning.

\begin{tabular}{|c|}
\hline Engagement and Motivation \\
Knowledge and Understanding \\
Performance and Action \\
Reflection and Critique \\
Judgment and Design \\
Commitment and Identity
\end{tabular}

\section{Figure 1. Shulman's Table of Learning.}

Our model conceptualizes student learning within occupational therapy and clinical laboratory science at our institution. We moved the pieces around until it made sense for how our students learn. Based on the verbatim from students, our experience as professionals, and the structure of the curriculum, and using the components from The Table of Learning, we developed the following model. 


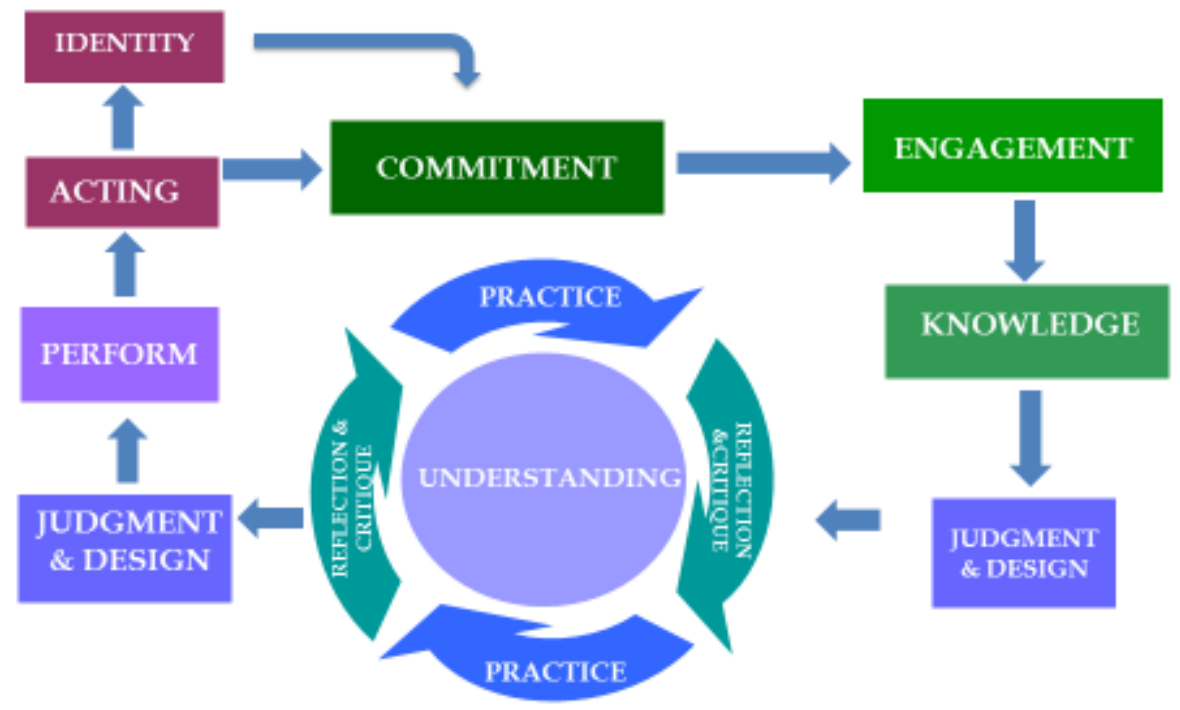

Figure 2. Visual representation of student learning in CLS and OT. Using the taxonomy pieces of Shulman's Table of Learning.

Based on the results of our study, our model (figure 2) starts with commitment as most of the students in OT and CLS enter each program with a commitment to the profession and to helping people. Commitment to the profession is confirmed, developed, and reinforced at various times as they move through the curriculum. The programs are similar in that students' engagement with certain populations (OT) and certain laboratory areas (CLS) tends to wax and wane throughout the curriculum. This waxing and waning of engagement in professional curriculum may be part of the “fog of learning” that Tagg (2010) encourages educators to explore in all fields (Tagg 2010, p.4).

The arrangement of our model places understanding in the center of the cycle containing reflection, critique, and practice; highlighting the importance of practice. We believe that practice experiences in professional education are particularly prone to fogginess. It is "foggy" for students when they encounter a new situation in practice. It is "foggy" for educators in identifying these situations, provide time for reflection, and support the learning process for students to internalize 
new knowledge. Donald Schon, in his book The Reflective Practitioner (1983) suggested that students need to "reflect-in-action" and "on-action" in order to search for the "internalized knowledge” gained from technical content knowledge and practice experiences and resolve the uncertainty. In addition, Schon purported that further building of "internalized” knowledge occurs when the student/practitioner "constructs a manageable problem from a problematic situation" (Schon, 1983 p. 170). It is crucial that educators allow time for reflection and critique about the uncertain situations students face to build on internalized knowledge. Schon's description of the theory-practice gap is evident when professionals attempt to apply previously attained internalized knowledge to practice, such as designing a new intervention in OT and problem-solving procedural and/or technical issues in CLS. Likewise, students test their content knowledge within the classroom, on-campus laboratory, clinical rotations and fieldwork experiences when they encounter an uncertainty. Do we allow enough time for reflection within the current CLS and OT curriculum structure that supports judgment and design?

Challenges exist in our programs to provide students with the opportunity, support and time to engage in reflection and critique to support judgment and design. A relatively small amount of reflection-in-action and on-action occurs within the time constraints of the on-campus laboratory, clinical rotation, and the OT level I fieldwork experience. In CLS, education programs have been faced with cutting back on time spent in each discipline rotation time due to a reduced workforce available to teach. The increase in automation of laboratory testing has caused educators to pause and reflect on what is a reasonable time to spend rotating through each laboratory area. The demands of OT clinicians makes finding time to reflect with the student difficult. The need to cover an ever increasing amount of content knowledge limits opportunities for reflection within the classroom. We would argue that educators in health care professional education, should be 
concerned with appropriate learning strategies that continue to allow a way to close the "gap" when students apply theory to practice in the classroom, on-campus laboratory, clinical rotations, and fieldwork. It is essential to do so, as the understanding acquired through practice and reflection connotes a form of ownership of the knowledge and actions of the profession. Implications for our programs (CLS and OT) includes assessment of placements to support student learning while meeting the demands of clinical practice. If we are not "closing the gap” for students, perhaps, the placement is not appropriate for our students.

Movement toward judgement and design occurs as students utilize knowledge gained. This is represented in our model by a smaller judgement and design box immediately following the knowledge box. Certainly, students begin to judge and design interventions in OT classroom casework and in level I fieldwork and begin to hone problem solving skills (judgement and design) in the CLS on-campus laboratory. Practice provides the opportunity for knowledge to be applied and understanding confirmed; it is a proving ground where students can learn their new role and validate their ideas. Participation in practice, reflection and critique leads to understanding and revisions in design and judgment which leads to reasoned professional action. In our view, practice without reflection and critique will not lead to successful judgement and design. We strive to have practice and reflection in CLS and OT support students to begin to judge and design with the knowledge they have at hand and build on the ability to act and perform within the profession. The ability to perform as a member of the profession promotes identity and reaffirms and deepens commitment to the profession.

Throughout their movement through the programs, students begin to socialize to their respective professions. One cannot ignore that in professional education the interactions of students with peers and experts builds the affective domain of professional education as students learn the 
professional expectations, beliefs, and etiquette of their respective profession. In our opinion, socialization with peers and mentors in the student laboratory, clinical rotation in CLS, and fieldwork in OT is critical as a model for how to act as a member of the profession. Socialization occurs throughout the program as students continuously evaluate their capacity to act and receive feedback on their performance as members of the profession.

Socializing students into the profession calls educators to be cognizant of every opportunity to make professional knowledge explicit through feedback. Students must have the opportunity to observe, reflect, and question practice to illuminate the less easily articulated pieces of professional knowledge. For example, when an educator at the clinical site demonstrates a skill, the student observes many nuances in how that particular task is carried out. The task is part of the technical know-how; however, the application of the task contains behaviors that students observe. In the occupational therapy program students may or may not be supervised by an OT during Level I fieldwork. The absence of peers and experts in the field may make it difficult for students to observe and reflect on what is happening during practice. There are also challenges when students are placed with an OT supervisor. The OT supervisor because of practice demands may not have the time to engage in critical discourse needed for students to develop their understanding of practice. In the CLS program, students are placed in every clinical rotation with peers and experts in the field. Unlike OT, there is not a lack of critical discourse between CLS students and members of the field because students have access to professionals from the field throughout the curriculum. But like OT, CLS educators are challenged with providing enough time for reflection and critique.

Through our use of The Table of Learning we were able to examine learning without thought of beginning or end. Shulman (2002) posits that taxonomies are not hierarchical. We agree with Shulman that learning is a dynamic circular process, best represented by a model that is not linear; 
there may not be a "single first stage" (Schon, 2002 p. 42). Playing with The Table of Learning allowed us to examine the process of how students may attain judgement and design, and ultimately be able to perform and act as members of the profession. Our model can be used to illustrate student learning both within courses and across the curriculum as students engage in both classroom and clinical experiences.

Furthermore, Shulman expressed concern that The Table of Learning pieces may be used to understand learning in merely a cognitive sense. Educators often do not pay attention to the affective aspect of student learning. Through interviews and focus groups we elicited their perceptions, attitudes, and feelings surrounding learning and we found that student engagement is linked to attitudes, feelings about content and learning experiences. Our discovery that the affective domain exists within the Table of Learning, as evidenced by our model, allows educators in professional programs to be confident that they will uncover the attitudes and beliefs of their students.

\section{Final Thoughts}

In order to adequately prepare students for practice, professional education must provide students with more than just the competencies and skills to do a job. Our goal is to show employers of our students that the alignment of learning in our programs meets the level of an entry-level practitioner. Sullivan and Rosin (2008) remind us, as educators in professional programs, that we need to be cognizant of our responsibilities to foster in our students the ability to "learn to blend knowledge, skill and appropriate attitude in response to unique situations” (Sullivan \& Rosin, 2008 p. xxi., preface). Our work, utilizing The Table of Learning, and subsequently the design of our model allowed us as educators from two separate programs to examine the learning process. As educators, we stepped back and viewed student learning with a shared language. Indeed, practice, reflection and critique, judgement, and design all include and an affective piece. 
The common framework of our model provides the ability for educators in professional programs to understand student engagement, when and how students develop commitments and motivations, when and how they reflect, how they apply theory to practice, and how they begin to make judgments as a member of the profession. For professional programs, understanding how students learn can help implement pedagogy that supports learning to develop professionals who can perform and act in complex and uncertain situations. Other professional programs can gain information about student learning from using our model to support the deliberate design of curriculum; form syllabi, learning objectives, to designing practice assessments that will support professional development. For example, practice assessments occur throughout the OT and CLS curriculum. We have learned from the use of our model that time for reflection and critique should be deliberate. Students are given guided questions in practice to reflect on their experience; but have we allowed enough time for critique of their initial judgements? We know from our model that these steps are crucial in the formation of actions.

Shulman (2004) warns us against "pedagogical solitude”, namely, educators working within their discipline, prohibiting colleagues from learning and sharing the nature of teaching in professional programs (Shulman, 2004 p. 455). Ongoing interdisciplinary conversations, such as ours, provides an integrated perspective on teaching and learning and sheds light on the similarities and differences in student learning that occur within a professional program and across professional programs.

In order to continue this interdisciplinary conversation our future research will focus on the application of our model to other professional programs in our college, such as nursing, dietetics, and social work. We encourage educators in professional programs in other institutions to engage 
in this interdisciplinary dialogue; play with our model of student learning; critique it, refine and revise it.

\section{References}

Bragg, A. K. (1976). The socialization process in higher education (ERIC/Higher Education Research Report No. 7). Washington, DC: American Association for Higher Education. (ERIC Document Reproduction Service No. 132909).

Carnevale, A., Cheah, B., and Strohl, J. (2013). Hard Times 2013 College majors, unemployment and earnings: Not all college degrees are created equal. Center on Education and the Workforce: Georgetown University. Retrieved from https://cew.georgetown.edu/wpcontent/uploads/HardTimes2015-Report.pdf

Eraut, M. (2000). Non-formal learning and tacit knowledge in professional work. British Journal of Educational Psychology, 70, 113-136.

Eastern Michigan University Institutional Research and Information Management (IRIM). 2014. Quick facts: trend of fall term. [data file]. Retrieved from:

http://irim.emich.edu/quick_facts.php?\#

Kibek, P. (2008). The worsening shortage of lab staff: What's being done to turn it around? Clinical Laboratory News, 34(5), 1-4.

McKinney, K. (2013). Introduction to SOTL in and across disciplines. In The scholarship of teaching and learning in and across disciplines. Bloomington IN: Indiana University Press.

Sabari, J. (1985).Professional socialization: Implications for occupational therapy education. American Journal of Occupational Therapy, 39(2): 96-102.

Schon, D. (1983). The reflective practitioner. How professionals think in action. U.S: Basic Books.

Shulman, L.S. (2002). Making differences: A table of learning, Change, 34(6), 36-44.

Shulman, L. S., \& Hutchings, P. (2004). Teaching as community property: Essays on higher education (1st ed.). San Francisco: Jossey-Bass.

Shulman, L.S, \& Fenstermacher, G.D. (2008). Foreword. In Sullivan, W.M. \& Rosin, M.S. (Eds.), A New Agenda for Higher Education: Shaping a Life of the Mind for Practice, (highlights). New York: Carnegie/Jossey-Bass.

Sullivan, W.M., \& Rosin, M.S. (2008). Preface. In Sullivan, W.M. \& Rosin, M.S. (Eds.), A New Agenda for Higher Education: Shaping a Life of the Mind for Practice, (highlights). New York: Carnegie/ Jossey-Bass.

Tagg, J. (2010). Dispelling the fog of learning through SOTL, International Journal for the Scholarship of Teaching and Learning, 4(2), 1-7. 
Understanding (n.d.). In Merriam Webster Dictionary online. Retrieved from http://www.merriam-webster.com/dictionary/understanding.

U.S. Department of Education, National Center for Education Statistics. (2015). Digest of Education Statistics, 2013 (NCES 2015-011) Retrieved

from: http://nces.ed.gov/fastfacts/display.asp?id=37 